\title{
Descentralización y desigualdad en el desarrollo regional y local de China
}

$\mathrm{U}$ sualmente la información que el mundo recibe de los medios sobre China ha sido sobre las espectaculares cifras macroeconómicas que este país ha logrado mantener por 25 años consecutivos. Aun cuando la veracidad de dichas estadísticas ha sido cuestionada, el crecimiento económico de China es ya una realidad palpable dentro de la economía global. Por dar solo algunos ejemplos: el crecimiento promedio del PIB de China de 1978 a 2000 fue de 9.4 por ciento, y después de un descenso a los 7.1 puntos porcentuales en 1999, en 2003 la economía creció 9.1 por ciento (MOFCOM, 2004); China es el mayor receptor de inversión extranjera directa [IED] (más de 5000 millones de dólares en 2003 y más de 2500 millones de dólares en el primer cuarto de 2004); además de ser la quinta potencia comercial (el monto total de su comercio exterior asciende a 6000 millones de dólares, y sus exportaciones constituyen 4.4 por ciento del total mundial); China es la segunda economía más grande del mundo después de la de Estados Unidos; ${ }^{1}$ sus reservas de divisas extranjeras ascienden a 25000 millones de dólares; China es el mayor productor de televisiones, aires acondicionados, cámaras fotográficas, teléfonos, etcétera.

Pero, ¿qué significan estas cifras en la realidad económica china? ¿Cómo se distribuye ese crecimiento económico dentro del territorio chino? ¿Cuáles actores socioeconómicos y políticos se han beneficiado más de ese crecimiento? Las zonas económicas especiales (SEz) son quizá las que han recibido mayor atención en los medios y por parte de los inversionistas extranjeros. Fuera de eso se sabe poco sobre la formulación de las estrategias y políticas económicas y de desarrollo, y sobre cómo és-

* Instituto de Estudios Internacionales, Universidad Tecnológica de Sydney (UTS), Australia.

ORCID http://orcid.org/0000-0001-8416-6769 tas son implementadas a escala regional y local. China no constituye una entidad económica unificada, sino que representa un Estado continental formado por una serie de economías regionales. Durante el período maoísta las experiencias locales tenían ya un papel importante en la formulación de las políticas nacionales, aun cuando la economía estuviera centralmente planificada. El concepto de autonomía local ha sido desde entonces reconocido por los líderes del Partido Comunista como un elemento imprescindible en el desarrollo de un país del tamaño y diversidad del de China.

A raíz de la reforma económica iniciada a finales de 1978, la relación entre el gobierno central y los gobiernos subnacionales ha experimentado cambios significativos. Parte importante del proceso de transición hacia una economía regida por el mercado ha sido la reforma institucional y administrativa a escala nacional. La descentralización administrativa y la delegación de autoridad y de recursos hacia los gobiernos locales han sido los programas más extensivamente implementados en los últimos 25 años de reforma. El principal objetivo de dicha descentralización se ha dirigido a la mejora en la eficiencia y en la liberalización de las economías regionales.

Éste fue el primer intento para separar las estructuras de la administración económica de las de la administración gubernamental, reconociendo que no todas las actividades económicas tenían que ser dirigidas por el gobierno, sin que esto significara un total divorcio entre el aparato gubernamental y el sector económico. A través de la gradual reestructuración del sector paraestatal, gran parte de las empresas administradas directamente por el gobierno central pasarían a manos de los gobiernos subnacionales y, en algunas instancias, 
éstas funcionarían independientemente de los gobiernos locales (Goodman, 1989: 23).

Esta nueva distribución jurisdiccional se manifestó también en la autoridad presupuestaria. Hasta 1979 el sistema presupuestario había estado altamente centralizado y dependía casi en su totalidad de los recursos de las empresas paraestatales, las cuales hasta 1984 representaban la mayor fuente de ingresos del gobierno. Los presupuestos provinciales eran determinados y asignados por el gobierno central, lo cual limitaba la implementación de iniciativas locales de desarrollo. Sin embrago, a principios de los años ochenta, el gobierno necesitaba ganarse el apoyo de los líderes provinciales para promover el proceso de reforma económica. Entonces el gobierno central accedió a descentralizar la autoridad presupuestaria, al mismo tiempo que se desligaba de una serie de responsabilidades fiscales hacia las provincias.

A raíz de esta descentralización presupuestaria - aunada a la disminución de ingresos provenientes de las empresas paraestatales - los ingresos del gobierno central se redujeron drásticamente, limitando su capacidad para cumplir sus obligaciones con el desarrollo de infraestructura, apoyos al campo, subsidios de precios, etcétera (Shirk, 1993: 173). En un esfuerzo por recentralizar parte de la extracción de impuestos, el gobierno implementó una nueva reforma fiscal en 1994, mediante la cual el impuesto al valor agregado se convertiría en la principal fuente de ingresos tributarios (Eckaus, 2003: 73-74). A partir de esta reforma fiscal el nivel de ingresos del gobierno central se ha recuperado, desde su nivel más bajo (2.56 por ciento del PIB en 1993) a su nivel actual (cercano al 18 por ciento del PIB).
Una tendencia permanente desde el comienzo de la reforma ha sido la continua delegación de responsabilidades fiscales hacia los niveles gubernamentales más bajos. Las transferencias del gobierno central hacia los gobiernos subnacionales han experimentado una reducción continua, creando un desequilibrio entre la responsabilidad y la capacidad fiscal de los gobiernos locales. Por una parte, en las provincias de la costa este - las mayores receptoras de inversión doméstica y extranjera- el dinamismo económico y el crecimiento en la actividad industrial y comercial se han transformado en crecientes ingresos tributarios para los gobiernos locales. Hacia el interior del país —especialmente para los gobiernos de los condados y las ciudades pequeñas- la recaudación de los recursos necesarios para promover el desarrollo se ha transformado en un ejercicio cada vez más complicado. La falta de recursos en las regiones económicamente menos dinámicas, por ejemplo, ha afectado la provisión y la calidad de los servicios públicos, al mismo tiempo que el costo de estos servicios para los usuarios se incrementa.

Muchos gobiernos locales se han visto forzados a adquirir grandes deudas públicas, a fin de poder financiar el desarrollo de infraestructura, el sistema de pensiones, la educación básica y los servicios de salud. En algunos casos, instituciones gubernamentales y empresas del Estado no cuentan siquiera con recursos para pagar los sueldos de sus empleados.

A fin de obtener ingresos suficientes para cumplir con las responsabilidades del gasto gubernamental, los gobiernos locales (en los niveles gubernamentales más bajos) han recurrido de manera creciente al uso de recursos extrapresupuestarios (REP). Aun cuando estos ingresos no son incluidos en la tabulación del presupuesto oficial, los REP se han convertido 
en parte integral del presupuesto de los gobiernos locales. De hecho, en las dos últimas décadas los REP han crecido a un ritmo más rápido que el sistema tributario oficial. En 2002 el Banco Mundial señalaba que el presupuesto formal de China era pequeño comparado con los recursos extrapresupuestarios. Durante ese mismo año el presupuesto formal representaba alrededor de 14 por ciento del PIB, mientras que los ingresos extrapresupuestarios ascendían a 20 por ciento del PIB (World Bank, 2002).

En teoría, las imposiciones extrapresupuestarias deben de obtener autorización oficial de una o más oficinas del Ministerio de Finanzas; en la práctica, muy pocas son puestas para su aprobación (Eckaus, 2003: 74-75). Los REP son casi siempre generados mediante cuotas impuestas arbitrariamente a empresas o en servicios públicos (colegiaturas, servicios de salud, cobros por la pavimentación de calles, etcétera). De igual manera, debido a que estos recursos no son contabilizados en el presupuesto oficial, las autoridades locales son más discretas al utilizarlos en las prioridades económicas de la localidad.

Aunque la corrupción por parte de las autoridades locales es una realidad, la dependencia de los REP representa la única solución inmediata a la creciente carga en las responsabilidades financieras de los gobiernos locales. Esta práctica, sin embargo, tiene también consecuencias negativas para la planeación económica, debido a la variabilidad del monto y disponibilidad de los REP. La formulación del presupuesto gubernamental se vuelve pasiva y reactiva, y muchas de las veces dicho presupuesto no refleja las necesidades locales de desarrollo o de la agenda nacional. Esta mala administración del presupuesto a escala local es reflejo de una reforma fiscal incompleta, la cual necesita establecer una división más clara de las responsabilidades y funciones financieras del gobierno central y los gobiernos locales.

A nivel del condado y de las ciudades pequeñas, el sistema es considerado como in- justo e informal, sujeto a cambios a discreción de las autoridades en niveles más altos (Wong, 2002). Efectivamente, los gobiernos en la jerarquía urbana más baja son los más desfavorecidos en la distribución de recursos, y muchos están experimentando una severa crisis financiera (Han Jun, 2002).

\section{Conclusiones}

Los nuevos arreglos organizacionales e institucionales desencadenados por la reforma económica han influenciado claramente los procesos del desarrollo chino, incluyendo las formas en que los diferentes niveles gubernamentales toman parte en dicho desarrollo. La descentralización administrativa y de recursos, por ejemplo, ha incrementado la autonomía local, dándole mayor control a los gobiernos locales para formular sus propias estrategias de desarrollo y, consecuentemente, convirtiéndolos en agentes de cambio en el proceso de modernización de China. $\mathrm{Al}$ mismo tiempo, sin embargo, las responsabilidades fiscales de los gobiernos locales se han acrecentado.

Las provincias de la costa este, gracias a su dinamismo económico, han logrado generar suficientes recursos para promover exitosamente el desarrollo de su infraestructura y servicios públicos. Otras regiones del interior no han tenido el mismo éxito y muchos están experimentando severas crisis financieras que afectan de forma directa el desarrollo local.

Mientras que la reforma económica avanza en la República Popular de China (RPC), se ha hecho evidente que los logros del rápido crecimiento económico no han sido experimentados de manera equitativa por las diferentes regiones y entre los distíntos grupos sociales. Las crecientes desigualdades regionales han presionado al gobierno central a redirigir su atención en el desarrollo de la costa este hacia las regiones menos desarrolladas del centro y el oeste del país. De igual manera - y a fin de mantener la estabilidad social- el gobierno central echó a andar la reforma del sis- 
tema de seguridad social, reconociendo que la estabilidad social sigue siendo uno de los prerrequisitos no solo de una transición económica exitosa, sino también de la continuación de la supremacía política del Partido Comunista Chino. La promoción del desarrollo económico y social al interior del país es ahora el reto más importante para China, cuyo éxito dependerá en gran medida del apoyo que se le brinde al desarrollo local.

\section{Bibliografía}

Eckaus, R. S. (2003) "Some consequences of fiscal reliance on extrabudgetary revenues in China", China Economic Review, vol. 14, núm. 1.

Goodman, David S. G. (1989) "Political Perspectives", en David Goodman (ed.) China's Regional Development, Routledge for the Royal Institute of International Affairs.

Han Jun (2002) "Public Finance Crisis in Chinese Counties and Towns: Performance, Causes, Impact and Measures", paper presented at the International Workshop on China's Rural Public Finance. ASEM, the Research Department of Rural Economy, State Council Development Research Centre, and the World Bank. Pekín, 7 de diciembre. моғсом (2004) Ministry of Commerce of the People's Republic of China. http://english.mofcom.gov.cn/article/ 200406/20040600235857_1.xml.

Shirk, Susan L. (1993) The Political Logic of Economic Reform in China. University of California Press.

Wong, Christine (2002) "Rural public finance in the context of fiscal reform in China". Paper presented at the International Workshop on China's Rural Public Finance. ASEM, the Research Department of Rural Economy, State Council Development Research Centre, and the World Bank. Pekín, 7 de diciembre.

World Bank (2002) “China national development and subnational finance: a review of provincial expenditures" Report 22951-CHA.

\section{Nota}

1 Basado en PPP. www.nationmaster.com/country/ch/ Economy (accesado el 4 de marzo de 2004).

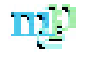

